\title{
Energy-Based Evaluations on Eucalyptus Biomass Production
}

\author{
Thiago L. Romanelli, ${ }^{1}$ Marcos Milan, ${ }^{1}$ and Rafael Cesar Tieppo ${ }^{2}$ \\ ${ }^{1}$ College of Agriculture "Luiz de Queiroz" (ESALQ), University of Sao Paulo (USP), Avenida Padua Dias 11 C.P.9, \\ 13418-900 Piracicaba, SP, Brazil \\ ${ }^{2}$ Graduate Program in Engineering of Agricultural Systems, College of Agriculture "Luiz de Queiroz" (ESALQ), \\ University of Sao Paulo (USP), Avenida Padua Dias 11 C.P.9, 13418-900 Piracicaba, SP, Brazil
}

Correspondence should be addressed to Thiago L. Romanelli, romanelli@usp.br

Received 13 July 2012; Revised 21 September 2012; Accepted 30 October 2012

Academic Editor: Brian C. McCarthy

Copyright (C) 2012 Thiago L. Romanelli et al. This is an open access article distributed under the Creative Commons Attribution License, which permits unrestricted use, distribution, and reproduction in any medium, provided the original work is properly cited.

\begin{abstract}
Dependence on finite resources brings economic, social, and environmental concerns. Planted forests are a biomass alternative to the exploitation of natural forests. In the exploitation of the planted forests, planning and management are key to achieve success, so in forestry operations, both economic and noneconomic factors must be considered. This study aimed to compare eucalyptus biomass production through energy embodiment of anthropogenic inputs and resource embodiment including environmental contribution (emergy) for the commercial forest in the Sao Paulo, Brazil. Energy analyses and emergy synthesis were accomplished for the eucalyptus production cycles. It was determined that emergy synthesis of eucalyptus production and sensibility analysis for three scenarios to adjust soil acidity (lime, ash, and sludge). For both, energy analysis and emergy synthesis, harvesting presented the highest input demand. Results show the differences between energy analysis and emergy synthesis are in the conceptual underpinnings and accounting procedures. Both evaluations present similar trends and differ in the magnitude of the participation of an input due to its origin. For instance, inputs extracted from ores, which represent environmental contribution, are more relevant for emergy synthesis. On the other hand, inputs from industrial processes are more important for energy analysis.
\end{abstract}

\section{Introduction}

The Commercial forests in Brazil focus primarily on Pinus spp. (1.79 million ha) and Eucalyptus spp. (4.51 million ha), [1]. Planted forests are a biomass alternative to the exploitation of natural forests. Silviculture systems are economic and thermodynamic units, subject simultaneously to constraints of profit loss, as well as, the laws of physics. So, for planning and assessing forestry operations, both economic and noneconomic factors must be considered, demanding a systemic view [2].

A dependence on finite resources causes economic, social, and environmental concerns. After a certain level, there are neither technical nor economic reasons for the field management to be intensified, regarding the output result due to the higher use of inputs (fertilizer, etc.). Thus, there are conflicting requirements in trying to reach higher yields from a limited agricultural area through the minimum use of energy embodied in the inputs. This conflict can be diminished through the analysis of the interaction between the crop and the energy applied to its management. The evaluation of how production systems demand and supply energy is vital [3]. Energy analyses establish flows, identify the total demand, the energy balance, and the energy return on the invested energy $\left(E_{\mathrm{ROI}}\right)$, as well as, the energy embodied (intensity) in a product or service. Energy balance refers to the net energy gain per area while $E_{\mathrm{ROI}}$ refers to the ratio of energy made available by the required energy in a process and it can be understood as "energy profitability" [4, 5]. Energy intensity is the energy embodied directly and indirectly per unit of the obtained product. One must consider all input energy, not only the applied sources (electricity, fuels), but also the energy embodied in input production and services.

Regarding the more complex system and the services the environment provides to production system, the concept of emergy (spelled with an "m") was introduced, to properly account for the quality of matter, energy, and information flows within systems, including their degradation due to 
second law losses during transformation processes [6]. By definition, emergy is the amount of available energy (or exergy) of one type (usually solar) that is directly or indirectly required to provide a given flow or storage of energy or matter. Although there are numerous studies comparing stand management methods (rotation times, reforestation alternatives, and multiple-use management) [7-9], the operational processes for intensive forest management are relatively standardized in our study area. Thus, there is a greater need for studies of commercial forestry that compare energy and material flow requirements of operational techniques to maximize sustainability within the confines of existing feasible alternatives (i.e., cognizant of the simultaneous profit objective). Field efficiency, maintenance schedules, and, more generally, sensitivity of production systems to subtle operational changes are usually evaluated in economic costs and benefits, but rarely for their comparative sustainability.

Considering the search for sustainability in production systems, the insertion of noneconomic parameters in the decision making in eucalyptus (Eucalyptus spp.) in Sao Paulo state, Brazil, this study aimed to compare eucalyptus biomass production through energy embodiment of anthropogenic inputs and resource embodiment including environmental contribution (emergy). We explore the sensitivity of results to three alternative agricultural inputs used to adjust soil $\mathrm{pH}$ (limestone, ash, and sludge), and delineate operational resource requirements by type (renewable, nonrenewable, and purchased) and phase (e.g., planting, fertilizing, and harvesting).

\section{Material and Methods}

Our analysis of eucalyptus production cycles comes from the municipality of Itatinga in Sao Paulo state, Brazil. We focus on production systems on existing plantation lands because implantation on new lands in Brazil is significantly constrained by land limitation. In order to determine material flow and input requirements per hectare in the production system, data on the operational details of the production system were obtained for a 1,700 ha plantation owned and managed by a private company, which operates 300,000 ha of plantation throughout Brazil. We used the company's internal reports as the basis of our analysis. Data are for operations through a single rotation, excluding transportation of harvested biomass to utilization facilities. These data were checked through field measurements and personal communication with the foresters. Harvesting is done on 6- to 8year rotation with relatively uniform average yields regionally ( $41.5 \mathrm{~m}^{3} \mathrm{ha}^{-1} \mathrm{yr}^{-1}$; range 19.0 to $70.0 \mathrm{~m}^{3} \mathrm{ha}^{-1} \mathrm{yr}^{-1}$ ).

Our study was developed through the following steps: (1) determination of the diagram and energy flows of a production system of eucalyptus in Sao Paulo state, Brazil; (2) evaluation of its performance using indicators such as energy balance, energy return on investment, and energy intensity; (3) determinate emergy synthesis of eucalyptus nursery and biomass production; (4) use a proposed algorithm to determine these indicators for scenarios and sensibility analysis, the basic scenario is lime (applied to adjust the soil acidity) and two alternative scenarios, which used ash and sludge, instead of lime.

The evaluation of the energy flows considered the fuel consumption, the machinery depreciation, the labor, and the inputs directly applied in each mechanized operation performed. The mechanized operations were performed in the following sequence: lime application; subsoiling (plus fertilizer and pesticide application); furrowing; planting; irrigation; spraying (herbicide); fertilizer application (1400-15 in the 3rd month); spraying (herbicide); fertilizer application ( $\mathrm{KCl}$ in the 8th month); spraying (herbicide); fertilizer application (14-00-15 in the 2nd year); harvesting. Ant control and replanting are operations that are performed according to the need and they were considered in this study.

Through the analysis of energy flows, one can establish the pattern of energy flow, identify the total demand, and determine the energy performance that can be reflected by the net gain as well as by the ratio of energy made available regarding the energy invested. The indicators used to evaluate this performance are energy balance $\left(E_{B}\right), E_{\mathrm{ROI}}$ (energy return on investment), and energy intensity $\left(E_{I}\right) . E_{B}$ refers to the net energy gain per area while $E_{\mathrm{ROI}}$ refers to the ratio of energy made available by the required energy in a process and it can be understood as "energy profitability." $E_{I}$ is the embodied energy per unit of the obtained product. $E_{I}$ is an important indicator for products which have no energetic use (e.g., fiber). These indicators are determined through the energy input $\left(E_{\mathrm{IF}}\right)$ and output $\left(E_{\mathrm{OF}}\right)$ flows. For the $E_{B}$ to be determined (1), the energy input flow $\left(E_{\mathrm{IF}}\right)$ is subtracted from the output flow $\left(E_{\mathrm{OF}}\right)$, resulting in the net gain per area.

Some authors refer to the energy balance as the ratio of energy made available and the required by a production system $[6,10]$. However, in this study, we adopted the ratio term of $E_{\mathrm{ROI}}(2)[4]$ :

$$
\begin{gathered}
E_{B}=E_{\mathrm{OF}}-E_{\mathrm{IF}}, \\
E_{\mathrm{ROI}}=\frac{E_{B}}{E_{\mathrm{IF}}},
\end{gathered}
$$

where $E_{B}=$ energy balance, $\mathrm{MJ} \mathrm{ha}^{-1} ; E_{\mathrm{IF}}=$ energy input flow, $\mathrm{MJ} \mathrm{ha}^{-1} ; E_{\mathrm{OF}}=$ energy output flow, $\mathrm{MJ} \mathrm{ha}^{-1} ; E_{\mathrm{ROI}}=$ energy return on investment, $\mathrm{MJ} \mathrm{MJ}^{-1}$. This consideration is due to the recognition of some authors of different energy quality reflecting their entropy level and origin. If this consideration was not done, $E_{\mathrm{ROI}}$ would be nondimensional.

Considering the possibility of the harvested biomass not being used for energetic purposes, it is reasonable to relate the product obtained and the energy input in the production system. This is indicated by the energy intensity $\left(E_{I}\right)$ :

$$
E_{I}=\frac{E_{\mathrm{IF}}}{Y}
$$

where $E_{I}=$ energy intensity, $\mathrm{MJ} \mathrm{m}^{-3} ; Y=$ yield, $\mathrm{m}^{3} \mathrm{ha}^{-1}$.

The algorithm used to determine the material flow of inputs indirectly applied in the mechanized operations was developed by [11], as showed in Figure 1.

The process starts (1) (Numbers between brackets indicate steps in the flow chart presented in Figure 1.) with 


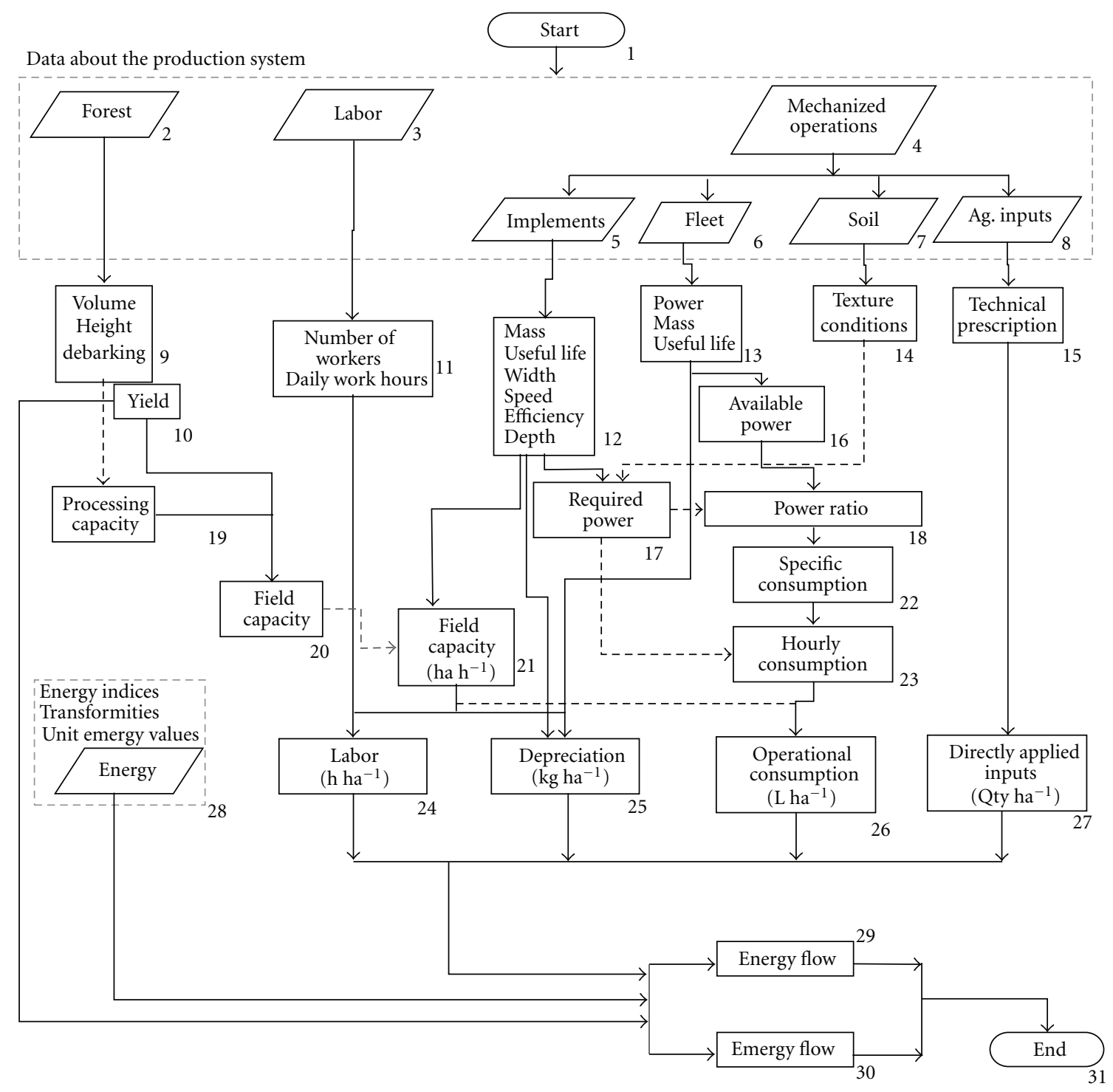

FIGURE 1: Flow chart developed to determine energy and emergy flows [11].

the data input about the planted forest (2), applied labor (3) and the mechanized operations (4). The mechanized operations set covers implements (5) and the fleet (fleet here considered approaches self-propelled machines, such as tractors, harvesters, self-propelled sprayers.) (6), as well as the prescription of agricultural inputs (8). Soil condition (7) affects the traction demand (14). The data about the forest (9) (tree volume, average tree height, and debarking during harvesting) determine the processing capacity, $\mathrm{m}^{3} \mathrm{~h}^{-1}$ (19). The ratio of processing capacity and yield $(10), \mathrm{m}^{3} \mathrm{ha}^{-1}$, provides the operational field capacity $\left(F_{C}\right)$ for harvesting (20), ha h $\mathrm{h}^{-1}$. In this case, harvesting $F_{C}$ is not based on width, speed or on the work efficiency as in the other operations (21). Harvesters present processing capacity and the forest conditions determine the operation efficiency. Some studies present specific data for subsystems that are part of harvesting [12]. The data on implements (12) and fleet (13) are mass, useful life, work width and speed, work efficiency and depth (soil tillage). Mass and useful life provide the physical depreciation of the machinery (25). Width, speed, and field efficiency determines field capacity (21). Depth and soil condition (14) affect the power requirement (17). The power of the fleet (6) determines available power (16). The ratio (18) between required (17) and available power (16) determines the specific fuel consumption (22). The specific fuel consumption and the required power (17) determines of the hourly fuel consumption $\left(\mathrm{L} \mathrm{h}^{-1}\right)$ (23), which is related to the field capacity provided by the operational consumption $\left(\mathrm{L} \mathrm{ha}^{-1}\right)$ (26). One must emphasize that fuel consumption may vary due to the tractor features such as tire type, weight, and work speed [13]. The labor data-number of workers and daily work period (11)_related to the $F_{C}(21)$ determines the human labor per area (24). Since application rate of agricultural inputs are determined by technical prescription (15), the quantity of inputs (volume, mass, and units) per area is provided directly (27). Multiplying each 
variable, labor (24), material depreciation (25), fuel (26), and inputs (27) by their respective energy index (28) is possible to determine the energy input of each variable in the production system. Summing the individual contributions provides the methodology indicator (29).

For the energy evaluation, the multiplication of the energy content (28) of wood and yield (10) provides the energy output flow $\left(E_{\mathrm{OF}}\right)$. The input flow and yield (10) indicate the energy intensity of the harvested biomass. $E_{\mathrm{ROI}}$ and energy balance $\left(E_{B}\right)$ are determined by the input and output flows.

We followed environmental accounting protocols previously outlined $[9,14,15]$, to determine Emergy Synthesis for this system, which starts with the development of an energy systems diagram that summarizes the resource basis of the operation. This diagram is used to identify key inputs to each system. From the diagram, we compiled a list of direct and indirect inputs necessary for production; these flows are allocated to renewable, nonrenewable, and purchased (Figure 2) at this stage.

This list forms the basis of an environmental accounting table, with each input listed along with the physical flow and the reported units. To meaningfully compare resources of different kinds, we convert physical units ( $g, J)$ by UEVs (sej unit ${ }^{-1}$ ) tabulated from the existing literature to estimate emergy (sej). All tables include the source of both the biophysical flow (e.g., mass of fertilizer used per hectare per year) and the UEV assigned to that flow (e.g., sej $\mathrm{g}^{-1}$ for that fertilizer). In all tables, UEVs are corrected for the new global emergy baseline [7]. Key outputs of an emergy synthesis include computing UEVs for the products (sej J ${ }^{-1}$ or sej $\mathrm{g}^{-1}$, depending on the product) and a systems-level metric for comparative assessment among competing systems based on the manner in which emergy is partitioned within a given system (Figure 1). From these flow partitions, we compute the emergy yield ratio (EYR), which is the ratio of emergy yield from a process to the emergy costs:

$$
\mathrm{EYR}=\frac{R+N+F}{F},
$$

where $R$ (renewable), $N$ (local nonrenewable), and $F$ (purchased) are partitions in the overall emergy budget of the production process. EYR is a measure of how much a process contributes to the larger scale system, and a system-level metric of energy return on investment [16].

Biomass from these systems is harvested for pulp and cellulose but could alternatively be used for energy; throughout, we provide UEVs for both mass $\left(\mathrm{sej} \mathrm{g}^{-1}\right)$ and energy $\left(\mathrm{sej} \mathrm{J} \mathrm{J}^{-1}\right.$ ) to reflect these potential dual uses. We note, however, that for the particular operation we have only considered the energy content of the pulpwood (limbs and bark have been ignored); thus, the UEV per unit energy $\left(\right.$ sej J $\left.{ }^{-1}\right)$ is probably an overestimate. The operation examined here uses two mechanized harvesters operating continuously to fell the trees; eight laborers per harvester per shift operate the machinery and manually delimb and crosscut the trees into logs with chainsaws. Two forwarders transport the logs to roadside; costs of transport to a subsequent utilization facility are not included.
After the determination of these indicators the use of this algorithm is ended (30).

2.1. Scenarios and Sensibility Analysis. The base scenario (lime is a conventional material used to raise soil $\mathrm{pH}$ ) was the production system evaluated. The two alternatives (ash and sludge) regarding the soil acidity adjustment were also analyzed.

Our goal was to determine whether there are meaningful differences in overall resource requirements between these three alternatives - two of which are recycled products. We note here that, although ash and sludge have considerable $\mathrm{N}, \mathrm{P}_{2} \mathrm{O}_{5}$, and $\mathrm{K}_{2} \mathrm{O}$ content, fertilization rates were held constant for all three scenarios. Dry matter (DM) application rates were $7,700 \mathrm{~kg} \mathrm{DM} \mathrm{ha}^{-1}$ for sludge and $3,000 \mathrm{~kg} \mathrm{DM} \mathrm{ha}^{-1}$ for ash. The costs of transport of the amendment to the production site are computed based on emergy transportation costs of $2.4 E 11 \mathrm{sej} \mathrm{Mg}^{-1} \mathrm{~km}^{-1}$; we assume $100 \mathrm{~km}$ transport in all cases. From the perspective of sustainability analysis, it is essential to note that we have not embedded this analysis in the larger scale system, wherein sludge and ash represent waste products that would require emergy for disposal and wherein this emergy is obviated by use for soil $\mathrm{pH}$ management. That is, where the amendments are recycled from wastes, the emergy of their input may be neglected, and the only costs attributed to the production system are those associated with the transport of the material. We explore the implications of this assumption by comparing the UEV values computed for the base case ( $\mathrm{pH}$ management using $1,000 \mathrm{~kg} \mathrm{ha}^{-1}$ limestone, with those computed for the ash and sludge amendments with and without their emergy included. For energy analysis, the input energy was the indicator compared to the base scenario. For the first case "Raw", we include the emergy in the sludge or ash in the total emergy use; in the second case "Recycled" we neglect the emergy in the amendment and only tabulate the transportation costs.

To perform sensitivity analysis, critical variables were selected. So, the effect in other indicators could be measured. This technique was applied in the mechanized system management by [17]. Through this analysis, improvements can be made in the sustainability of forestry production. Changes in the uses of labor, agricultural inputs, machinery, and in the machinery management were suggested to be compared in the base scenario (lime as soil acidity corrector). The base scenario was changed to $10 \%$ more field efficiency $\left(+F_{E}\right) ; 10 \%$ less used power $\left(-P_{\mathrm{ow}}\right) ; 10 \%$ more useful life $\left(+U_{L}\right) ; 10 \%$ less labor $\left(-L_{\mathrm{ab}}\right) ; 10 \%$ less agricultural input $\left(-A_{I}\right)$, except the seedling use. The scenario $+F_{E}$ represents the tractor-implement set or the self-propelled machine (e.g., combine) operating on 10\% more area per time. For this to be possible, it is necessary for some of the following management changes: increase the machinery width, increase the work speed, to have a better plot shape, and better plan maneuvers. The scenario $-P_{\text {ow }}$ was suggested to evaluate the effects on the overall energy demand of the fuel consumption. The scenario $+U_{L}$ aimed to measure the improvement of a better maintenance and/or machinery durability. The scenario $-L_{\mathrm{ab}}$ was suggested to check the 


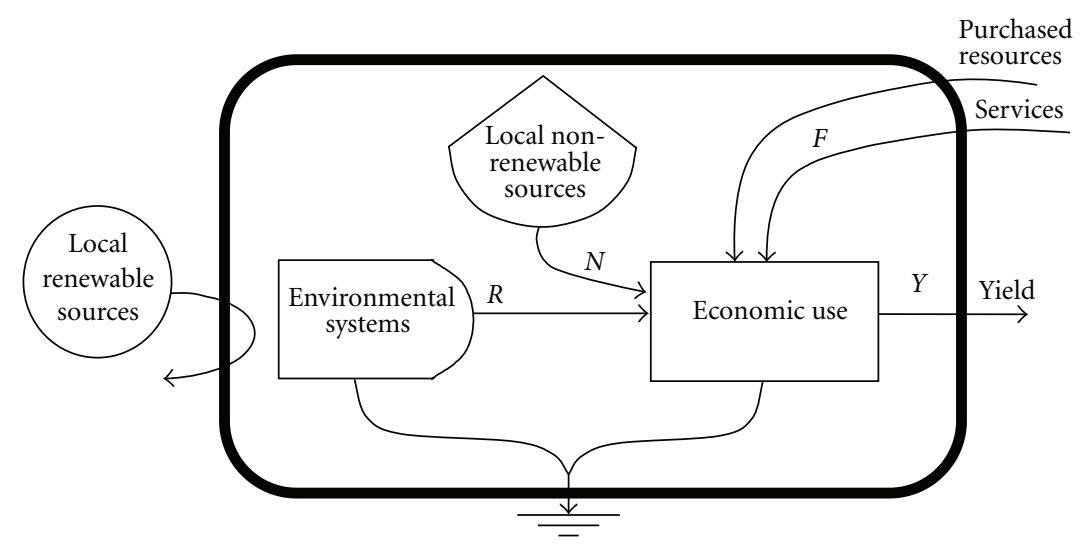

Indicators:

Yield $(Y)=R+N+F$

Emergy Yield Ratio $(E Y R)=Y / F$

Emergy Investment Ratio $(\mathrm{EIR})=F /(R+N)$

Environmental Loading Ratio $(\mathrm{ELR})=(F+N) / R$

FIGURE 2: Systems diagram showing aggregated resource flows for environmental production. Emergy flows along thick lines; thin lines to the heat sink represent the loss of available energy/exergy that occurs with all transformations. $R$ : renewable; $N$ : nonrenewable; $F$ : purchased.

effects of human labor use. And, finally, the scenario $-A_{I}$ explored the effect of better use of inputs through genetic developments, for instance.

\section{Results and Discussion}

3.1. Energy Analysis. Results of energy analysis were based in [17]. The physical aspects of biomass production, through its material flows for every mechanized operation were determined in [17] (Figure 3). The values of material flow were presented and grouped by their type with their respective embodied energy. The product of these two values results the energy input flow, which was calculated also considering the forest rotation period (energy input flow divided by time) for further comparison with other biomass production systems.

Although these numbers give the impression that eucalyptus is an efficient energy source, one must highlight that this analysis only approaches the inputs acquired in the market, not considering the soil, climate, and hydric conditions that propitiates the presented production potential. Considering the average sunlight in the region $\left(3.91 \mathrm{GJ} \mathrm{ha}^{-1} \mathrm{~s}^{-1}\right.$ ) through a typical seven-year rotation, the total solar energy applied would be $8.5610^{5} \mathrm{GJ}$, which represents $2.3610^{5}$ times more energy than that presented in all agricultural inputs or 397 times more energy than the contained in the calorific power of the harvested wood. There are methodologies just as emergy synthesis that approach the environmental contribution $[9,18,19]$, but since these production means are free they are not taken into account in the energy flow determination.

The values obtained, considering the incident solar energy, agree with the second law of thermodynamics. Most authors, when discussing energy sources and renewable energy, do not mention that there is no energy generation such as it seems by observing data that exclude solar energy.
What really exists is the energy availability, through energy transformations and their intrinsic losses.

The net energy made available $\left(E_{B}\right)$ and the energy "profitability" $\left(E_{\mathrm{ROI}}\right)$ are both important for an energy source to be evaluated. But, in both indicators, the time spent on making the energy available is not considered. Relating these indicators with the period demanded for the forest to be harvest, one can obtain the annualized indicators, which allow the comparison of different production systems that surpass one-year period. On the other hand, the annualized indicators would overestimate annual crops which are grown in the better weather seasons that are not kept throughout the whole year.

For the use of the developed algorithm and its results to be validated; we looked for data available in the literature. Either the energy intensity of biomass [17] or the input energy [17] was used in this comparison. The results of the alternatives lime, ash, and sludge are between the lowest [20] and the highest values [21]. Although the amplitude of these values are considerable $61.6 \%$ (from 123.8 to $200 \mathrm{MJ} \mathrm{m}^{-3}$ ) the 26 years of difference between these papers show the difference on soil use in Sweden where both works were carried out.

The base scenario had the energy intensity $0.7 \%$ above the minimum found [20] and $16.9 \%$ and $37.7 \%$, respectively, below the minimum and maximum limits found in [21]. The algorithm presented results within the range provided by the references. The sludge scenario is closer to the maximum found although it represents a tropical production system. But this high energy content is due to the methodology which establishes the energy indicator according to the sludge's NPK content.

The greater amount of energy, demanded in the current production systems, is due to the intense adoption of agricultural inputs and machinery. Again, the sludge scenario stood 


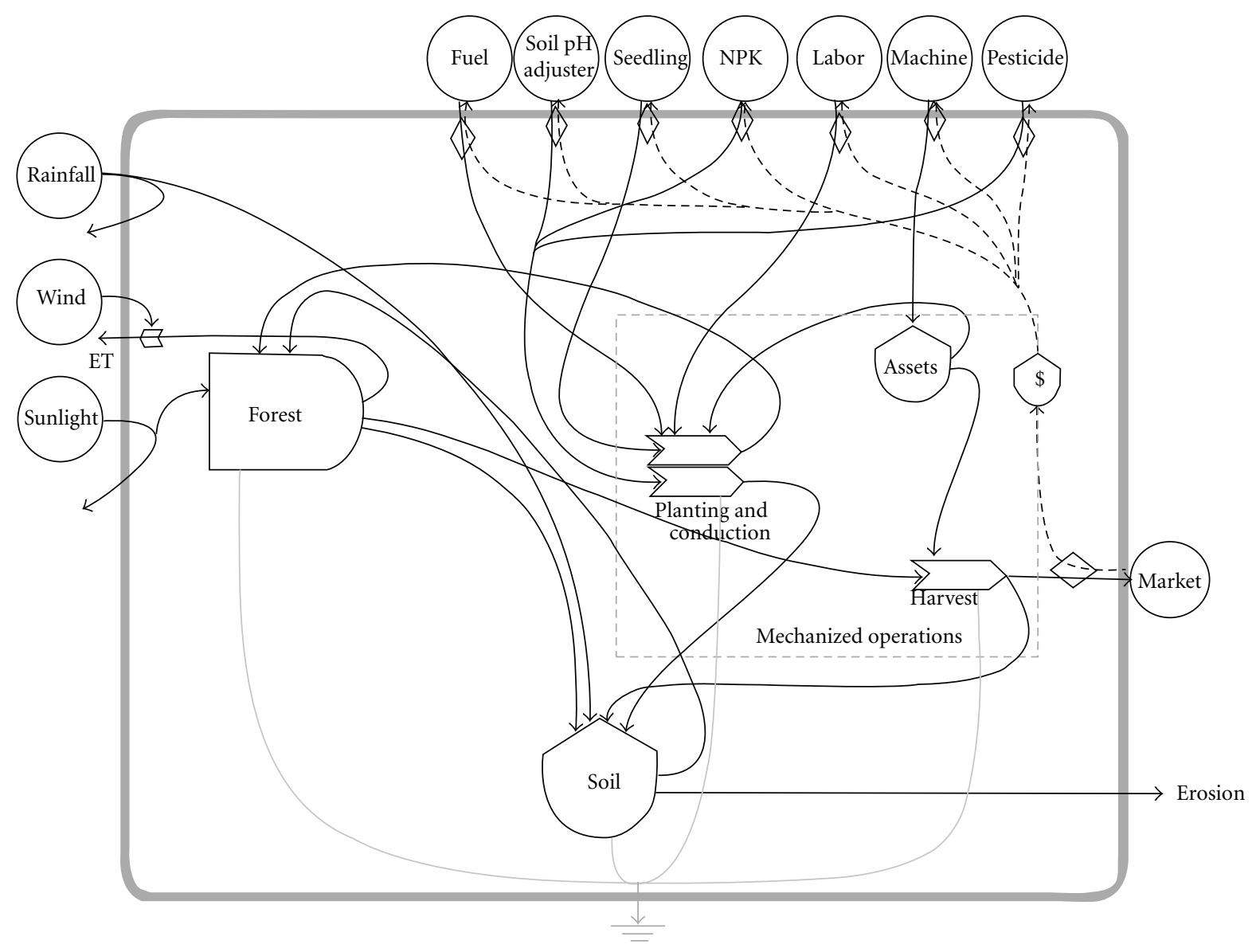

FIgURE 3: Systems diagram for Eucalyptus production system.

out from the others, with $39.30 \%$ greater energy demand than the second one [16]. This is explained by its higher content of industrialized nitrogen (the most energetically intense nutrient) and by the amount applied per area $\left(7,700.00 \mathrm{~kg} \mathrm{ha}^{-1}\right)$.

Besides lime, there is the possibility to use ash or sludge as a corrector of soil acidity by the production system evaluated; their characteristics are shown in [17].

The embodied energy of the alternative materials for soil acidity adjustment was determined considering their NPK content. This estimative does not seem to be the most appropriate one since the NPK content may not represent the actual energy content of the material. This method only regards the avoidance of synthesis or extraction the equivalent of nutrients. Although the alternative materials present more NPK content than lime, no difference on the fertilization planning is observed.

Due to the larger amount of alternative material (lime, ash, and sludge) applied to adjust soil acidity, the input energy increased, making them less environmentally attractive, according to the adopted indicators: energy intensity, $E_{\mathrm{ROI}}$, and energy balance [17]. The input energy was $5.7 \%$ and $57.2 \%$ higher for ash and sludge, respectively. The same differences were observed in the energy intensity comparison. Their $E_{\mathrm{ROI}}$ indices were $95.0 \%$ and $63.1 \%$ of the base scenario's index. Energy balance had a decrease lower than $1 \%$ for both.

For a better comparison among the alternative uses of ash and sludge, an analysis at a larger scale should be conducted. When ash and sludge (or other residues to be discarded) are used, society avoids the demand for landfills, transport, and storage. So, these indirect benefits could be taken into account as energy flows in the determination of the most environmental friendly option.

Fuel and fertilizers are responsible for $79.3 \%$ of the demanded energy (around 75\% in the ash and sludge scenarios). Fuel was the main energy intense input with around three times more than fertilizers. Since fuel is an input indirectly applied, distinctly from fertilizers, seedlings, and so forth, one highlights the importance of monitoring "how" the inputs are used and not only "how much" is applied. Machinery management plays a vital role on monitoring how the assets are being used. It was chosen to treat fertilizers (06-30-10, 14-00-15, and $\mathrm{KCl}$ ) as one group, in which they represented $27.7 \%, 59.4 \%$, and $12.9 \%$ of the energy content within the group, respectively.

However the results show eucalyptus production is an efficient energy source, one should highlight that this analysis only contemplates inputs purchased in the market, not taking into account environmental services such as soil, 
TABLE 1: Indices of energy efficiency considering solar energy.

\begin{tabular}{lcc}
\hline Indice & Value & Unit \\
\hline$E_{\mathrm{ROI}}$ & $-1,0$ & $\mathrm{MJ} \mathrm{MJ}^{-1}$ \\
$E_{\mathrm{ROI}}$ year $^{-1}$ & $-0,1$ & $\mathrm{MJ} \mathrm{MJ}^{-1}$ year $^{-1}$ \\
$E_{I}$ & $2,95 E+09$ & $\mathrm{GJ} \mathrm{m}^{-3}$ \\
$E_{M}$ & $-8,54 E+08$ & $\mathrm{GJ} \mathrm{ha}^{-1}$ \\
$E_{B}$ year $^{-1}$ & $-1,22 E+08$ & $\mathrm{GJ} \mathrm{ha}^{-1}$ year $^{-1}$ \\
\hline
\end{tabular}

weather, and hydric conditions, which provide the presented potential yield.

For practical means, considering the average insolation in the region $\left(3909 \mathrm{~kJ} \mathrm{ha}^{-1} \mathrm{~s}^{-1}\right)$ in the production cycle (seven years), the total solar energy applied in the system would be $8.56 \mathrm{E} 8 \mathrm{MJ}$. This value is $2.36 \mathrm{E} 5$ times higher than the energy amount demanded by the purchased inputs or 397 times higher than the calorific power of the produced biomass.

When considering sunlight energy (Table 1), the indicators follow the second law of thermodynamics, which states that all transformation of the energy from one kind to another promotes losses of energy (entropy). Most of the authors neglect this fact, when discussing about alternative energy, renewable and bioenergy, numbers such as those showed in adopted indicators [17] may make readers believe that there is energy generation instead of energy being made available at expenses of entropy increase.

Energy demand per operation and class of input data from the base scenario were used in order to detail the production system regarding its mechanized operations and inputs directly (agricultural inputs) and indirectly (fuel, depreciation, and labor) applied [17]. From the four production factors, fuel and agriculture inputs represent almost the whole energy demanded (95.8\%), getting the status of the most important for the search for environmental efficiency improvement. Regarding the mechanized operations, the harvesting is the most important by far. The magnitude of its values is due mainly to the low field capacity $\left(0.055 \mathrm{ha} \mathrm{h}^{-1}\right)$ which necessitates hourly consumption to be multiplied by the 18.20 hours taken for a single hectare $\left(290.50 \mathrm{~m}^{3} \mathrm{ha}^{-1}\right)$ to be harvested.

Besides harvesting, fuel is important also in irrigation due to the use of a tank-truck to support to the operation. Except for these operations, only the agricultural inputs directly applied are in list of the main energy demanders. Although pesticides present high-energy indices (80 to $450 \mathrm{MJ} \mathrm{L}^{-1}$ ), little volume is applied per area making them not an import energy demander. But, in a case of over dosage, although the little energy-demand effect serious environmental issues may be posed be toxicological effects.

3.2. Emergy Synthesis. Results of emergy synthesis was based in [9]. Figure 3 summarizes the resource basis of eucalyptus production, including renewable environmental inputs (rainfall, wind, and sunlight), natural stocks (soil loss), economic stocks (operation machinery), and purchased flows (fuels, $\mathrm{pH}$ management materials, propagules, fertilizer and pesticides, new machinery, and labor). Material flows and UEVs for each input are based in [9], however the values were set for the conditions found in [17], in which the support transport fleet was not taken into consideration (Table 2). Because the rotation cycle is 7 years from planting to harvesting, we report output data on both a total basis (after 7 years) and as an annualized flow.

Yields of pulpwood are reported in $\mathrm{m}^{3}$ and $\mathrm{J}$. The study system was assumed to yield $290.5 \mathrm{~m}^{3}$ of pulpwood $\left(41.5 \mathrm{~m}^{3} \mathrm{ha}^{-1} \mathrm{yr}^{-1}\right)$, representing 2.2E12 J of energy (pulpwood only) per hectare.

To evaluate the resource basis of this level of production, we start by summarizing the inputs for the case of using lime for $\mathrm{pH}$ management. As with the seedlings, a small number of the inputs represent most of the resource bases. In this case, the top four inputs comprise almost $90 \%$ of the total inputs. For all scenarios, the primary input to the process on both a full rotation and annual basis is transpired water (57-62\% of total use) delivered primarily from rainfall; limited irrigation is observed in some sites. Diesel (14-16\%), fertilizers (8-9\%), pH control (1-13\%), and labor (6-7\%) follow. Out of the total fraction of emergy agricultural inputs (fertilizers, lime, seedlings, and pesticides) and diesel fuel were the largest fractions at $54.10 \%$ and $26.70 \%$, respectively (Table 3). Labor, another purchased input, represents $17.80 \%$ of the total use, which contrasts strongly with the seedling production system, where labor represents almost 30\% of total use. Final output indices, which relate the resource basis for production with physical yields, are reported in Table 3. The UEV was 9.6E03 sej J $J^{-1}$, and the EYR was 2.01 for the base case in which lime is used for $\mathrm{pH}$ control.

3.3. Detailed Analysis of Operations. In an effort to understand operational requirements for each phase of stand management, we decompartmentalized the production system into operational stages (e.g., harvest, $\mathrm{pH}$ management, and fertilization) and report the emergy required in the form of inputs (agrochemicals and lime), diesel fuel, and labor for each (Table 3). Each line in this table is the percentage of total purchased inputs ( $F$ in Figure 2 ) for each entry; we omit the contribution of machinery depreciation here, which represents only $1.5 \%$ of total purchased emergy use. Harvesting requires most of the purchased emergy inputs (operational work capacity is $0.55 \mathrm{ha} \mathrm{h}^{-1}$ ), almost all in the form of diesel and labor; $\mathrm{pH}$ management was next. This finding suggests that, from the perspective of increasing ecological efficiency, the primary focus should be on harvesting efficiency and $\mathrm{pH}$ management. Most of the emergy for lime application is in the lime itself, whereas for irrigation, the primary resource was not water but the diesel required to distribute the water. Further, the roles of fertilization (12.1\% of total purchased emergy over three applications) and herbicide application (2.5\% of total purchased emergy; included in "Other" in Table 3) over the entire rotation are comparatively small from an ecological efficiency perspective. In total, the indirect inputs (diesel and labor) make up almost 55\% of the total purchased emergy, reinforcing the need to look at both direct material requirements for production and indirect requirements. 
TABLE 2: Emergy evaluation of eucalyptus plantation (7-year cycle); yields are for pulpwood only.

\begin{tabular}{|c|c|c|c|c|c|c|}
\hline \multirow{2}{*}{ Note } & \multirow{2}{*}{ Item } & \multirow{2}{*}{$\begin{array}{l}\text { Quantity } \\
\text { unit ha }^{-1}\end{array}$} & \multirow{2}{*}{ Unit } & \multirow{2}{*}{$\begin{array}{c}\text { UEV } \\
\text { sej unit }^{-1}\end{array}$} & \multicolumn{2}{|c|}{ Solar emergy flow } \\
\hline & & & & & Per rotation $E 12$ sej ha ${ }^{-1}$ & Per year E12 sej ha ${ }^{-1} \mathrm{yr}^{-1}$ \\
\hline \multicolumn{7}{|c|}{ Environmental inputs } \\
\hline 1 & $\begin{array}{l}\text { Actual } \\
\text { evapotranspiration }\end{array}$ & $3,85 E 11$ & $\mathrm{~J}$ & 30,576 & $11,775.50$ & $1,682.21$ \\
\hline 2 & Topsoil loss & $70 E 03$ & $\mathrm{~g}$ & $7.18 E 08$ & 50.00 & 7.14 \\
\hline \multicolumn{7}{|c|}{ Purchased loss } \\
\hline 3 & Diesel oil & $529.20^{*}$ & $\mathrm{~L}$ & $3.90 E 12$ & $2,063.80$ & 294.84 \\
\hline 4 & Machinery & 17,700 & g & $6.70 E 12$ & 119.00 & 17.00 \\
\hline 4 & Labor & $3.03 E 08$ & $\mathrm{~J}$ & $4.50 E 06$ & $1,362.26$ & 194.61 \\
\hline 6 & Fertilizer (06-30-10) & $2.60 E 05$ & $\mathrm{~g}$ & $4.6 E 09$ & $1,202.95$ & 171.85 \\
\hline 6 & Fertilizer (14-00-15) & $4.00 E 05$ & $\mathrm{~g}$ & $1.50 E 09$ & 578.34 & 82.62 \\
\hline 7 & Formicide & 1,000 & g & $2.50 E 10$ & 24.86 & 3.55 \\
\hline 8 & $\mathrm{KCl}$ & $1.50 E 05$ & $\mathrm{~g}$ & $1,50 E 09$ & 229.28 & 32.75 \\
\hline 3 & Lubrificant oil & 22.80 & $\mathrm{~L}$ & $3.85 E 12$ & 87.78 & 12.54 \\
\hline 7 & Scout & 7.60 & $\mathrm{~L}$ & $2.49 E 13$ & 188.97 & 27.00 \\
\hline 9 & Propagules & 1,845 & Unit & $1.60 E 11$ & 295.00 & 42.20 \\
\hline 10 & Water & 5.56 & $\mathrm{~L}$ & $1.26 E 09$ & 7.00 & 1,00 \\
\hline \multirow[t]{3}{*}{11} & Lime & $1.0 E 06$ & g & $1.68 E 09$ & $1,680.00$ & 240,00 \\
\hline & Transport lime to site & 100.00 & $\mathrm{t} \mathrm{km}^{-1}$ & $2.40 E 11$ & 24.00 & 3.43 \\
\hline & Total inputs & & & & & $2,812.74$ \\
\hline \multicolumn{7}{|c|}{ Outputs } \\
\hline 12 & Harvested pulpwood & $290.50^{\dagger}$ & $\mathrm{m}^{3}$ & $\mathrm{ST}_{1}$ & $19,457.44$ & $2,779.63$ \\
\hline \multirow[t]{5}{*}{13} & Harvested pulpwood & $2.16 E 12^{\S}$ & $\mathrm{J}$ & $\mathrm{ST}_{2}$ & $19,457.44$ & $2,779.63$ \\
\hline & $\mathrm{ST}_{1}$ & \multicolumn{3}{|c|}{ UEV harvested biomass (volume) } & $6.70 E 12$ & sej $\mathrm{m}^{-3}$ \\
\hline & \multirow{3}{*}{$\mathrm{ST}_{2}$} & \multirow{3}{*}{\multicolumn{3}{|c|}{ UEV harvested biomass (energy) }} & $9.57 E 11$ & sej $\mathrm{m}^{-3} \mathrm{yr}^{-1}$ \\
\hline & & & & & $9.02 E 02$ & sej $\mathrm{J}^{-1}$ \\
\hline & & & & & $1.29 E 02$ & sej $J^{-1} \mathrm{yr}^{-1}$ \\
\hline
\end{tabular}

\footnotetext{
${ }^{\dagger}$ Assuming use of wood as biomass for pulp and cellulose mills.

$\S$ Assuming use of pulpwood as biomass for energy; these data do not include energy in nonpulp products (bark and limbs), which might be used when energy is the principal output.

(1) UEV for evapotranspiration $=3.10 E 4 \mathrm{sej} \mathrm{J}^{-1}[22]$, evapotranspiration $=\left(7,796 \mathrm{~mm} \mathrm{ha}^{-1}\right) *\left(1.00 E 4 \mathrm{~L} \mathrm{~mm}^{-1} \mathrm{ha}\right) *\left(1 \mathrm{~kg} \mathrm{~L}^{-1}\right) *(4.94 \mathrm{E} 3 \mathrm{~J} \mathrm{~kg}-1)$.

(2) Topsoil loss based on the organic matter content $=\left(5.4 E 4 \mathrm{kcal} \mathrm{kg}^{-1} \mathrm{OM}\right) *(1,28 \% \mathrm{OM}) *\left(4.17 E 3 \mathrm{~J} \mathrm{Kcal}^{-1}\right) *\left(2.4 E 5 \mathrm{sej} \mathrm{J} J^{-1}[23]\right)=7.18 E 11 \mathrm{sej} \mathrm{kg}{ }^{-1}$.

(3) Diesel UEV and emergy content [6] $=\left(1.32 E 8\right.$ J galão $\left.{ }^{-1}\right) *\left(1\right.$ gallon $\left.3.8 \mathrm{~L}^{-1}\right) *\left(1.1 E 5 \mathrm{sej} \mathrm{J}^{-1}\right)=3.85 E 7 \mathrm{sej} \mathrm{L}^{-1}$.

(4) UEV for machinery depreciation $=\left(6.7 E 9 \mathrm{sej} \mathrm{g}^{-1}\right)$, [22] after [24], Per kg $=\left(6.7 E 9 \mathrm{sej} \mathrm{g}^{-1}\right) *\left(1,000 \mathrm{~g} \mathrm{~kg}^{-1}\right)=6.70 E 12 \mathrm{sej} \mathrm{kg} \mathrm{kg}^{-1}$.

(5) UEV for labor $4.5 E 6 \mathrm{sej} \mathrm{J}^{-1}$, by [25], energy of human labor $=(231.8 \mathrm{~h}) *\left(2500 \mathrm{kcal} \mathrm{dia}^{-1}\right) *\left(\right.$ day $\left.8 \mathrm{~h}^{-1}\right) *\left(4,186 \mathrm{~J} \mathrm{kcal}^{-1}\right)=3.03 \mathrm{E} 8 \mathrm{~J}$.

(6) UEVs: $\mathrm{K}_{2} \mathrm{O}=2.92 E 9$ sej g $^{-1} \mathrm{~K}[6] * 83 \% \mathrm{~K} \mathrm{~K}_{2} \mathrm{O}^{-1}, \mathrm{P}_{2} \mathrm{O}_{5}=2.99 E 10$ sej g $\mathrm{g}^{-1} \mathrm{P}[6] * 43,7 \% \mathrm{P} \mathrm{P}_{2} \mathrm{O}_{5}^{-1}, \mathrm{~N}=7,7 E 9$ sej g $\mathrm{g}^{-1} \mathrm{~N}[6], 06-30-10$ has 6\% N, 30\% $\mathrm{P}_{2} \mathrm{O}_{5}$ and $10 \% \mathrm{~K}_{2} \mathrm{O}$; and $14-00-15$ has $14 \% \mathrm{~N}$ and $15 \% \mathrm{~K}_{2} \mathrm{O}$.

(7) Based on the UEV of pesticides $2.49 E 10 \mathrm{sej}^{-1} * 1000 \mathrm{~g} \mathrm{~kg}^{-1}$ [25].

(8) UEV: $\mathrm{K}_{2} \mathrm{O}=2.92 E 9 \mathrm{sej} \mathrm{g}^{-1} \mathrm{~K}[6] * 1,000 \mathrm{~g} \mathrm{~kg}^{-1}, \mathrm{KCl} * 63 \% \mathrm{~K}_{2} \mathrm{O} \mathrm{KCl}{ }^{-1} * 83 \% \mathrm{~K}^{-} \mathrm{K}_{2} \mathrm{O}^{-1}$.

(9) UEV of a seedling is $1.6 E 11 \mathrm{sej}$, from [9].

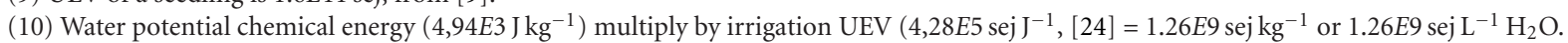

(11) Lime UEV (1.68E10 sej g $\left.{ }^{-1}\right)$ [6].

(12) Yield $=\left(41.5 \mathrm{~m}^{3} \mathrm{ha}^{-1} \mathrm{ano}^{-1}\right) *(7$ years $)=290.5 \mathrm{~m}^{3} \mathrm{ha}^{-1}$.

(13) Wood energy content $=\left(290.5 \mathrm{~m}^{3} \mathrm{ha}^{-1}\right) *\left(495 \mathrm{~kg} \mathrm{~m}^{-3}\right) *\left(1.5 E 7 \mathrm{~J} \mathrm{~kg}^{-1}\right)=2.16 E 12 \mathrm{~J} \mathrm{ha}^{-1}$, energy content [26] from [27].

$*$ [9] considered the purchased loss of diesel oil as $783.50 \mathrm{~L} \mathrm{ha}^{-1}$ because it was accounted for to support two trucks for repair and fuel used together for two harvester and forwarders.
}

3.4. Scenarios for Managing $p H$. Selection of $\mathrm{pH}$ control amendment and assumptions about how emergy is allocated in the system exert significant control over the results. Because we assumed no increases in fuel consumption, labor, and machinery depreciation with different applications, observed differences among $\mathrm{pH}$ management scenarios (Raw) are due to the amount and UEV of ash and sludge applied (Table 4). Assumptions about additional fuel and labor requirements are likely to be incorrect but are justified because the overall fuel and labor requirements are comparatively small (Table 3 ).

Resource requirements under the two alternative $\mathrm{pH}$ management scenarios are higher than those with limestone (Table 4) when the assumption is made to include the emergy 
TABLE 3: Percentage of purchased emergy inputs $(F)$ per operations and classes*.

\begin{tabular}{|c|c|c|c|c|c|}
\hline \multirow{2}{*}{ Operations } & \multicolumn{5}{|c|}{ Emergy demand per class (\%) } \\
\hline & Fuel & Emergy depreciation & Labor & Input & Total \\
\hline Harvest & 24.20 & 1.00 & 13.00 & 1.20 & 39.40 \\
\hline Limestone application & 0.20 & 0.00 & 0.10 & 22.00 & 22.30 \\
\hline Subsoiling + fertilizer + herbicide & 0.50 & 0.00 & 0.20 & 16.10 & 16.80 \\
\hline Fertilizer application (2nd year) & 0.20 & 0.00 & 0.10 & 4.70 & 5.00 \\
\hline Fertilizer application (3rd month) & 0.10 & 0.00 & 0.10 & 3.00 & 3.20 \\
\hline Fertilizer application (8th month) & 0.20 & 0.00 & 0.10 & 2.80 & 3.10 \\
\hline Planting & 0.10 & 0.00 & 0.80 & 2.00 & 2.90 \\
\hline Outros & 1.30 & 0.10 & 3.50 & 2.30 & 7.20 \\
\hline Total & 26.70 & 1.30 & 17.80 & 54.10 & 100 \\
\hline
\end{tabular}

${ }^{*}$ From $16.80 \%$ of the emergy total subsoiling, $15.70 \%$ represents fertilizer $(06-30-10)$ and $0.40 \%$ the herbicide.

TABLE 4: Alternatives for soil $\mathrm{pH}$ control.

\begin{tabular}{lcc}
\hline System parameter & Scenario & Ash \\
Sludge
\end{tabular}

${ }^{\dagger}$ Based on organic matter content $=\left(3,0 E 6 \mathrm{~g} \mathrm{ha}^{-1}\right) *\left(0,3363 \mathrm{~g} \mathrm{MO} \mathrm{g}^{-1}\right) *\left(5,4 \mathrm{kcal} \mathrm{g}^{-1}\right) *\left(4186 \mathrm{~J} \mathrm{kcal}^{-1}\right) *\left(1,2 \mathrm{E}^{\mathrm{sej} \mathrm{J}}{ }^{-1}[6]=9,45 E 11 \mathrm{sej} \mathrm{kg}{ }^{-1}\right.$. Ash composition by [28].

${ }^{\ddagger}$ Based on organic matter content $=\left(7,7 E 6 \mathrm{~g} \mathrm{ha}^{-1}\right) *\left(0,29584 \mathrm{~g} \mathrm{MO} \mathrm{g}^{-1}\right) *\left(5,4 \mathrm{kcal} \mathrm{g}^{-1}\right) *\left(4186 \mathrm{~J} \mathrm{kcal}^{-1}\right) *\left(1,2 E 5 \mathrm{sej} \mathrm{J}^{-1}[6]=8,31 E 11 \mathrm{sej} \mathrm{kg}{ }^{-1}\right.$. Sludge composition by [29].

in the amendment in the calculations (i.e., in addition to the transportation costs). In all cases, the transportation costs (assuming $100 \mathrm{~km}$ transport distance) are negligible. The emergy contained in the lime (1.70E16 sej) is nearly half that required for similar $\mathrm{pH}$ regulation when using ash, and approximately one-quarter of the emergy required for the same service using sludge. Synthesis indices for each scenario suggest that the resource basis for production is substantially higher with both ash (UEV $1.0 E 4 \mathrm{sej} \mathrm{J}^{-1}$ ) and sludge (UEV $1.2 E 4 \mathrm{sej} \mathrm{J}^{-1}$ ), which correspond to ecological efficiency declines of 5.6 and $22.7 \%$, respectively. Decreases in the EYR (less yield per unit investment) parallel this general conclusion.

When we neglect the emergy cost of the inputs (because they were created for another reason and are energetically free except for transportation), the UEV for pulpwood drops to $8.8 E 03$ and $8.9 E 03$ for the ash and sludge amendments, respectively; transportation costs assuming $100 \mathrm{~km}$ of travel are included in this Recycled scenario. The EYR shows parallel changes $(2.65,2.62$, and 2.34 for ash, sludge, and lime), with greater yield per unit investment for both $\mathrm{pH}$ control scenarios using recycled products. This result underscores the sensitivity of UEVs to assumptions about the system and the potential benefits of material recycling.

3.5. Analysis of Operations and $p H$ Management. One of the central conclusions of this work is that the indirect input requirements for operations (diesel and labor in particular) are large (55\% of total purchased emergy) in comparison with the products that are the direct inputs (fertilizers and pesticides). Further, most of the resource use is during harvest ( $42 \%$ of total purchased emergy), suggesting that efforts to improve efficiency should be focused there. However, we note that it is difficult to appreciably reduce fuel consumption at harvest because engine efficiency is relatively fixed, at least in the short term. The large amount of diesel demanded during harvest is due to high hourly consumption and low fieldwork capacity. As we observe below, improvements in this area will most likely come from increases in operational harvest work capacity $(\mathrm{OcH})$. The largest direct input in the base case was lime for $\mathrm{pH}$ control $(21 \%)$, followed by the suite of fertilizers used throughout the rotation (10\%). Among the fertilizers, phosphorus is the most emergyintense material, followed by nitrogen and potash. However, this relatively small fraction of the total purchased emergy that is in the form of fertilizers suggests that ecological efficiency is not greatly influenced by application rates and that the primary driver of recommended application rates should be considerations of downstream water quality.

Management of $\mathrm{pH}$ is a more complex problem. We showed that lime provided the service of $\mathrm{pH}$ regulation with the least resource input when we assumed that the emergy in the alternative amendments was included in the system budget. Use of waste products such as ash and sludge is, 
however, advocated on the basis of considerations of a larger system context. In particular, sludge and ash $\mathrm{pH}$ amendments represent by-products of industrial metabolism (i.e., waste); analyses at the next larger scale, which includes regional coproduction of both pulpwood and ash and/or sludge, are expected to show substantial benefits of their use, both by offsetting resource requirements of providing lime and also otherwise disposing of the waste. UEVs observed in a more realistic parallel analysis in which we assume that the emergy in each of the alternative amendments is zero (though retaining transportation costs) were markedly lower (8\%) than those for the lime scenario $(8.80 E 03,8.90 E 03$, and $9.60 E 03$ for ash, sludge, and lime, resp.). We justify this assumption of zero emergy in the material based on [6], who discusses the critical need for multiscale and multiuse analyses in public policy development. Specifically, if a product is a waste flow that can be diverted for productive use, then it is appropriate to omit its emergy from the quantitative analysis of resources required. Sensitivity to this assumption is clear, which is our rationale for providing both analyses.

3.6. Comparative Pulpwood Production. The UEV determined for harvested pulpwood biomass on an energy basis was $9.50 E 03 \mathrm{sej} \mathrm{J}^{-1}$. [24] reports UEV values for Eucalyptus spp. and Melaleuca spp. in Florida (United States) of $2.70 E 04 \mathrm{sej} \mathrm{J}^{-1}$ for harvested wood. This result suggests that the production costs in total resource units are $65 \%$ less in the Brazilian operation than in the comparable operation in the United States. Notably, this finding is due to both differences in yield (20.00 versus $12.40 \mathrm{Mg} \mathrm{ha}^{-1} \mathrm{yr}^{-1}$ ) for the Brazilian versus the US example, resp.) and differences in purchased inputs (1.20E15 versus $2.40 E 15$ sej ha ${ }^{-1} \mathrm{yr}^{-1}$, resp.). We note that the Brazilian operation is situated in a region that gets nearly twice as much rainfall as the Florida site.

A more general summary of the relevant literature [8, $15,24]$ across wood production systems, UEVs range from 9.50E03 sej J $\mathrm{J}^{-1}$ to $9.0 E 04 \mathrm{sej} \mathrm{J}^{-1}$ ) for hardwood production in Puerto Rico and North Carolina. A more meaningful comparison, however, is among only those systems oriented toward pulpwood production. Systems in which the primary output is not pulpwood appear in italics; among the others, the Brazilian example explored here has the lowest UEV, though short-rotation willow (salix spp.) production in southern Sweden had similar efficiency. The mean UEV for pulpwood appears to be near $1.80 E 04 \mathrm{sej} \mathrm{J}^{-1}$. Because UEV measures the resources required per unit of similar output (in this case J of energy), the Brazilian system under study here is a clearly desirable choice.

However, operations vary not only in their total resource requirements but also in their relative proportion of resources of different kinds. This difference can be important because society may be willing to accept slightly lower overall efficiency (i.e., higher UEV) if the resource base supporting a given operation is more reliant on local or renewable sources of emergy. This issue is discussed further in the context of producing electricity in [30].

The EYR is comparatively high for pulpwood production, revealing the substantial fraction of input emergy from "free" sources (local stocks and renewable flows). Notably, the willow system in southern Sweden and eucalyptus operation in Florida have lower EYR values, which imply lower return on investment. We note here, however, that the EYR values are not directly comparable with energy return on investment [26]. Despite the relative intensity of this production scheme, the EYR for this operation is comparatively low, even contrasted with that of other tropical plantation forest operations (slash pine EYR 2.82, siris EYR 2.32), both of which have substantially longer rotation times.

3.7. Energy versus Emergy. The methodology of energy flows follows an economic point of view, considering only the purchased inputs required by the production system. The energy gain represented either by the energy balance or the $E_{\mathrm{ROI}}$ does not take into account free resources such as the contribution of the environment in which the production system is located. On the other hand, emergy synthesis considers the role of the environment either in the production site or in the processing of obtaining an input. Comparing the share of mechanized operations (Table 5) and the inputs, one may notice that fertilizers from ores ( $\mathrm{K}$ and $\mathrm{P}$ ) impose higher impact than nitrogen (artificially synthetized) for emergy and the opposite for energy. Lime, another input exploited in ores, presents a major demand in emergy and not in energy, since in the latter it is considered by the energy content in its extraction process.

In the both methods, the harvesting presented the highest demand, because in this operation the volume of fuel (diesel) demand is high, for the energy analysis (56.7\%) as well as emergy synthesis (39.4\%). Secondly, for energy analysis, the operation subsoiling + fertilizer + herbicide represented $15.4 \%$ and $16.8 \%$ for the energy analysis (3rd place) and emergy synthesis, respectively. However, for emergy synthesis, the second highest emergy demander is lime application, since the the incorporated resource per unit of mass (UEV) of lime obtaining is higher. Comparing it to energy pointof-view, since energy in lime just represent its extraction and not the environmental contribution to have it accumulated in ores, lime application was only the fifth highest demand in energy analysis.

Among fertilizer applications, the 2nd and 3rd month applications have the same NPK concentration (14-00-15), thus, the energy demand as well as emergy synthesis is higher in 2nd year application, because the applied amount of fertilizer is bigger. The 8th fertilizer application was made with $\mathrm{KCl}$ and was applied in the same quantity in the $3 \mathrm{rd}$ month, it represents minor demand because of the smaller fuel consumption and has less incorporated energy and emergy.

Other mechanized operations have higher emergy demand than fertilizer applications, due to labor and fuel consumption, although input emergy in the fertilizers applications are superior. In the energy analysis, since the labor is the smallest representative, the other operations presented the second highest demand. However the fuel energy demand for the other operations is higher than fertilizer applications, therefore the labor has low energy value and high emergy value. 
TABLE 5: Energy and emergy demand per class for the mechanized operations.

\begin{tabular}{|c|c|c|c|c|c|}
\hline \multirow{2}{*}{ Mechanized operation } & \multicolumn{5}{|c|}{ Energy demand per class (\%) } \\
\hline & Fuel & Energy depreciation & Labor & Input & Total \\
\hline Harvesting & 51.0 & 2.2 & 1.0 & 2.4 & 56.7 \\
\hline Subsoiling + fertilizer + herbicide & 1.9 & 0.3 & 0.0 & 13.2 & 15.4 \\
\hline NPK (14-00-15) application (2nd year) & 0.4 & 0.1 & 0.0 & 8.6 & 9.1 \\
\hline NPK (14-00-15) application (3rd month) & 0.3 & 0.0 & 0.0 & 5.1 & 5.4 \\
\hline Limestone application & 0.3 & 0.0 & 0.0 & 4.6 & 4.9 \\
\hline $\mathrm{KCl}$ application (8th month) & 0.4 & 0.1 & 0.0 & 3.0 & 3.4 \\
\hline Others & 1.8 & 0.1 & 0.3 & 0.7 & 2.9 \\
\hline Planting & 0.2 & 0.1 & 0.1 & 1.9 & 2.2 \\
\hline Total & 56.3 & 2.9 & 1.4 & 39.5 & 100.0 \\
\hline \multirow{2}{*}{ Mechanized operation } & \multicolumn{5}{|c|}{ Emergy demand per class (\%) } \\
\hline & Fuel & Emergy depreciation & Labor & Input & Total \\
\hline Harvesting & 24.2 & 1.0 & 13.0 & 1.2 & 39.4 \\
\hline Limestone application & 0.2 & 0.0 & 0.1 & 22.0 & 22.3 \\
\hline Subsoiling + fertilizer + herbicide & 0.5 & 0.0 & 0.2 & 16.1 & 16.8 \\
\hline Others & 1.3 & 0.1 & 3.5 & 2.3 & 7.2 \\
\hline NPK (14-00-15) application (2nd year) & 0.2 & 0.0 & 0.1 & 4.7 & 5.0 \\
\hline NPK (14-00-15) application (3rd month) & 0.1 & 0.0 & 0.1 & 3.0 & 3.2 \\
\hline $\mathrm{KCl}$ application (8th month) & 0.2 & 0.0 & 0.1 & 2.8 & 3.1 \\
\hline Planting & 0.1 & 0.0 & 0.8 & 2.0 & 2.9 \\
\hline Total & 26.7 & 1.3 & 17.8 & 54.1 & 100.0 \\
\hline
\end{tabular}

3.8. Sensitivity Analysis. The sensitivity analysis for the energy demand was performed to quantify how much changes in the forest management would affect the energy efficiency. The energy input was the indicator chosen to be measured. All the scenarios were related according to [17] and, in each case, the suggested changes were evaluated through fixed $10 \%$ alterations in some production factors. The main result is that the choice of the material used to adjust soil acidity caused the higher difference in the energy efficiency. Within each alternative for soil acidity adjustment, the largest difference observed was 5.3\% (Table 6). The choice of material reached up to $55.6 \%$ of difference.

The higher improvement $(5.3 \%)$ in the energy performance was observed by the increase of field efficiency $\left(+F_{E}\right)$ and consequently, field work capacity. It was assumed that this improvement would not represent an increase in any other production factor (for instance, fuel). Through field efficiency the production factors indirectly applied (labor, machinery, and fuel) are reduced per area since all of them are related to the field work capacity to be expressed in area. Some management options may make this suggestion possible, such as plot shape better planned to decrease the time on maneuvers. The second best improvement came from the reduction of the agricultural inputs $\left(-A_{I}\right)$ with a similar effect $(4.0 \%)$. For this to be possible, techniques such as localized fertilizer application [31] present high potential to be implemented in forestry. The remaining scenarios did not change significantly the global efficiency of the production system. Thus, they would not pose as important factors to be addressed in the search of improvements on energy efficiency.
TABLE 6: Energy demand in the proposed scenarios (\%).

\begin{tabular}{lccc}
\hline \multirow{2}{*}{ Scenarios } & \multicolumn{3}{c}{ Alternatives for adjusting soil acidity } \\
& Lime & Ash & Sludge \\
\hline Base & 100.0 & 105.1 & 155.6 \\
$-P_{\text {ow }}$ & 99.9 & 105.0 & 155.5 \\
$-L_{\mathrm{ab}}$ & 99.9 & 104.9 & 155.4 \\
$+U_{L}$ & 99.8 & 104.8 & 155.3 \\
$-A_{I}$ & 96.0 & 100.6 & 146.1 \\
$+F_{E}$ & 94.7 & 99.7 & 150.2 \\
\hline
\end{tabular}

$-P_{\text {ow }}$ : decrease machinery power in $10 \% .-L_{\mathrm{ab}}$ : decrease labor in $10 \% .+U_{L}$ : increase in $10 \%$ on the machinery life cycle. $-A_{I}$ : decrease in $10 \%$ on inputs used. $+F_{E}$ : increase of $10 \%$ in field efficiency was based on width.

An important aspect to be emphasized about the sensitivities shown is that even little differences on efficiency can have substantial implications in the resource use efficiency. Although evaluated at the farm level or even stand level, one should keep in mind that forestry operations are performed in million of hectares. So, even slight improvements may represent a considerable value of fuel saved, for instance.

For the emergy synthesis, sensitivity analysis of total resource requirements to feasible operation changes are summarized in Table 7 relative to the base case detailed in Table 2. In each scenario, relative changes in total resource requirements are small (3\%), suggesting that the system is relatively insensitive to minor improvements in management. The most improved scenario was decreasing agrochemical inputs, followed by increasing operation capacity. Although no scenario showed marked variation, considering the area over 
TABLE 7: Sensitivity of emergy requirements to alternative management (base data 100).

\begin{tabular}{lccc}
\hline Scenario & Lime & Ash & Sludge \\
\hline Base & 100.0 & 106.0 & 124.4 \\
$+U_{L}{ }^{\S}$ & 100.0 & 105.9 & 124.3 \\
$-L_{\mathrm{ab}}{ }^{\natural}$ & 99.3 & 105.3 & 123.4 \\
$-P_{\mathrm{OW}}{ }^{\ddagger}$ & 99.0 & 105.0 & 123.4 \\
$+F_{E}{ }^{\dagger}$ & 98.4 & 104.3 & 122.7 \\
$-A_{l}{ }^{\dagger \dagger}$ & 97.9 & 103.3 & 119.9 \\
\hline
\end{tabular}

${ }^{\dagger}$ The increase of $10 \%$ in field efficiency was based on width, speed work, maintenance schemes and field shape. ${ }^{\ddagger}$ Decrease machinery power in $10 \%$. \$Increase in $10 \%$ on the machinery life cycle. ${ }^{~}$ Decrease in $10 \%$ in labor. ${ }^{\dagger \dagger}$ Decrease in $10 \%$ on inputs used (purchased input evapotranspiration and seedling were kept the same).

which operations occur, regional emergy savings could be significant. Furthermore, scenarios are at least partially independent, so the relative change with two or more modifications would be approximately the product of their marginal effects.

In both energy analysis and emergy synthesis, sensitivity analysis showed that the larger improvements in the environmental indicators were achieved by, individually, increasing field efficiency and decreasing the use of fertilizer. Changes in the sensitivity analysis are considered isolated without effects among the variables changed (e.g., less fertilizer application presents less necessity to refill the spreader, resulting in higher field efficiency). So, the decision making should consider all the possibilities that could cause these two effects (more field efficiency and less input use) in order to improve the environmental performance of the production system evaluated.

Energy analysis shows the economic point-of-view of a production system and emergy synthesis considers the energy memory embodied in natural resources, but both are options for those looking for reducing the environmental impact. The results show the differences between energy analysis and emergy synthesis are in the conceptual underpinnings and accounting procedures, as explained by [32]. Both present similar trends and differ in the magnitude of the participation of an input due to its origin. For instance, inputs extracted from ores, that is, environmental contribution, (e.g., phosphorus) is more important for emergy synthesis. On the other hand, inputs from industrial processes (e.g., nitrogen) is more important for energy analysis. Changes in the environmental indicators (UEV for emergy synthesis and input energy for energy analysis) had similar trend, but distinct magnitudes since, in emergy synthesis, the participation of local renewable inputs (evapotranspiration) were responsible for $60.5 \%$ of the total demand). For energy analysis, the whole demand was due to purchased goods (vis-à-vis less around 39.5\% in emergy synthesis).

\section{References}

[1] ABRAF, Statistical Year book of the Brazilian Association of Planted Forest Producers 2009, ABRAF, Brasília, Brazil, 2009.
[2] V. Tellarini and F. Caporali, "An input/output methodology to evaluate farms as sustainable agroecosystems: an application of indicators to farms in central Italy," Agriculture, Ecosystems and Environment, vol. 77, no. 1-2, pp. 111-123, 2000.

[3] T. L. Romanelli and M. Milan, "Energy balance methodology and modeling of supplementary forage production for cattle in Brazil," Scientia Agricola, vol. 62, no. 1, pp. 1-7, 2005.

[4] C. A. S. Hall, "The myth of sustainable development: personal reflections on energy, its relation to neoclassical economics, and Stanley Jevons," Journal of Energy Resources Technology, vol. 126, no. 2, pp. 85-89, 2004.

[5] R. Hammerschlag, "Ethanol's energy return on investment: a survey of the literature 1990-Present," Environmental Science and Technology, vol. 40, no. 6, pp. 1744-1750, 2006.

[6] H. T. Odum, Environmental Accounting: Emergy and Decision Making, John Wiley \& Sons, New York, NY, USA, 1996.

[7] H. T. Odum, S. J. Doherty, F. N. Scatena, and P. A. Kharecha, "Emergy evaluation of reforestation alternatives in Puerto Rico," Forest Science, vol. 46, no. 4, pp. 521-530, 2000.

[8] D. R. Tilley and W. T. Swank, "EMERGY-based environmental systems assessment of a multi-purpose temperate mixedforest watershed of the southern Appalachian Mountains, USA," Journal of Environmental Management, vol. 69, no. 3, pp. 213-227, 2003.

[9] T. L. Romanelli, M. J. Cohen, M. Milan, and M. T. Brown, "Emergy synthesis of intensive eucalyptus cultivation in São Paolo, Brazil," Forest Science, vol. 54, no. 2, pp. 228-241, 2008.

[10] T. L. Romanelli, H. D. S. Nardi, and F. A. Saad, "Material embodiment and energy flows as efficiency indicators of soybean (Glycine max) production in Brazil," Engenharia Agrícola, vol. 32, no. 2, pp. 261-270, 2012.

[11] T. L. Romanelli and M. Milan, "Material flow determination through agricultural machinery management," Scientia Agricola, vol. 67, no. 4, pp. 375-383, 2010.

[12] A. P. Souza, L. J. Minette, F. M. T. Moreira, C. C. Machado, and K. R. Silva, "Performance of slingshot machine in harvest subsystem for eucalyptus Forest," Revista Brasileira de Engenharia Agrícola e Ambiental, vol. 8, no. 2-3, pp. 316-320, 2004 (Portuguese).

[13] A. Lopes, K. P. Lanças, C. E. A. Furlani, A. K. Nagaoka, P. Castro Neto, and D. C. C. Grotta, "Fuel consumption of the tractor as a function tire type, ballasting and forward speed," Revista Brasileira de Engenharia Agrícola e Ambiental, vol. 7, no. 2, pp. 382-386, 2003 (Portuguese).

[14] M. T. Brown and S. Ulgiati, "Emergy-based indices and ratios to evaluate sustainability: monitoring economies and technology toward environmentally sound innovation," Ecological Engineering, vol. 9, no. 1-2, pp. 51-69, 1997.

[15] S. J. Doherty, P. O. Nilsson, and H. T. Odum, "Emergy evaluation of forest production and industries in Sweden," Research Report, Bioenergy Department, Swedish University of Agricultural Sciences, Uppsala, Sweden, 2002.

[16] C. Hall, P. Tharakan, J. Hallock, C. Cleveland, and M. Jefferson, "Hydrocarbons and the evolution of human culture," Nature, vol. 426, no. 6964, pp. 318-322, 2003.

[17] T. L. Romanelli and M. Milan, "Energy performance of a production system of eucalyptus," Revista Brasileira de Engenharia Agrícola e Ambiental, vol. 14, no. 8, pp. 896-903, 2010.

[18] O. Cavalett, J. F. D. Queiroz, and E. Ortega, "Emergy assessment of integrated production systems of grains, pig and fish in small farms in the South Brazil," Ecological Modelling, vol. 193, no. 3-4, pp. 205-224, 2006.

[19] A. C. I. Pizzigallo, C. Granai, and S. Borsa, "The joint use of LCA and emergy evaluation for the analysis of two Italian wine 
farms," Journal of Environmental Management, vol. 86, no. 2, pp. 396-406, 2008.

[20] J. E. Mattsson, "Energy of forest machines in Swedish forestry as a whole," in Seminar on Energy Aspects of the Forest Industries, pp. 321-330, Pergamon Press, Oxford, UK, 1979.

[21] S. Berg and E.-L. Lindholm, "Energy use and environmental impacts of forest operations in Sweden," Journal of Cleaner Production, vol. 13, no. 1, pp. 33-42, 2005.

[22] M. T. Brown and E. Bardi, Handbook of Emergy Evaluation Folio 3: Emergy of Ecosystems, Center for Environmental Policy, University of Florida, Gainesville, Fla, USA, 2001.

[23] M. J. Cohen, M. T. Brown, and K. D. Shepherd, "Estimating the environmental costs of soil erosion at multiple scales in Kenya using emergy synthesis," Agriculture, Ecosystems and Environment, vol. 114, no. 2-4, pp. 249-269, 2006.

[24] S. J. Doherty, Emergy evaluations and limits to forest production [Ph.D. dissertation], University of Florida, Gainesville, Fla, USA, 1995.

[25] S. Brandt-Williams, Handbook of Emergy Evaluation Folio 4: Emergy of Florida Agriculture, Center for Environmental Policy, University of Florida, Gainesville, Fla, USA, 2002.

[26] D. J. Mead and D. Pimentel, "Use of energy analyses in silvicultural decision-making," Biomass and Bioenergy, vol. 30, no. 4, pp. 357-362, 2006.

[27] P. Hakkila and M. Parikka, "Fuel resources from the forest," in Bioenergy from Sustainable Forestry: Guiding Principles and Practice, J. Richardson, R. Björheden, P. Hakkila, A. T. Lowe, and C. T. Smith, Eds., pp. 19-48, Kluwer Academic, Dodrecht, The Netherlands, 2002.

[28] V. Benedetti, "Use of the industrial residues at S. A. Ripasa and paper as inputs in the forest production," in Seminar About Use of the Industrial and Urban Residues in Forest, I. A. Guerrini, A. F. J. Bellote, and L. T. Büll, Eds., pp. 141-154, UNESP, Botucatu, Brazil, 1994.

[29] A. Franco, C. H. Abreu Junior, D. Perecin, F. C. Oliveira, A. C. R. Granja, and V. S. Braga, "Sewage sludge as nitrogen and phosphorus source for cane-plant and first ratoon crops," Revista Brasileira de Ciencia do Solo, vol. 34, no. 2, pp. 553-561, 2010 (Portuguese).

[30] M. T. Brown and S. Ulgiati, "Emergy evaluations and environmental loading of electricity production systems," Journal of Cleaner Production, vol. 10, no. 4, pp. 321-334, 2002.

[31] F. J. Pierce and P. Nowak, "Aspects of precision agriculture," Advances in Agronomy, vol. 67, pp. 1-85, 1999.

[32] M. T. Brown and R. A. Herendeen, "Embodied energy analysis and EMERGY analysis: a comparative view," Ecological Economics, vol. 19, no. 3, pp. 219-235, 1996. 

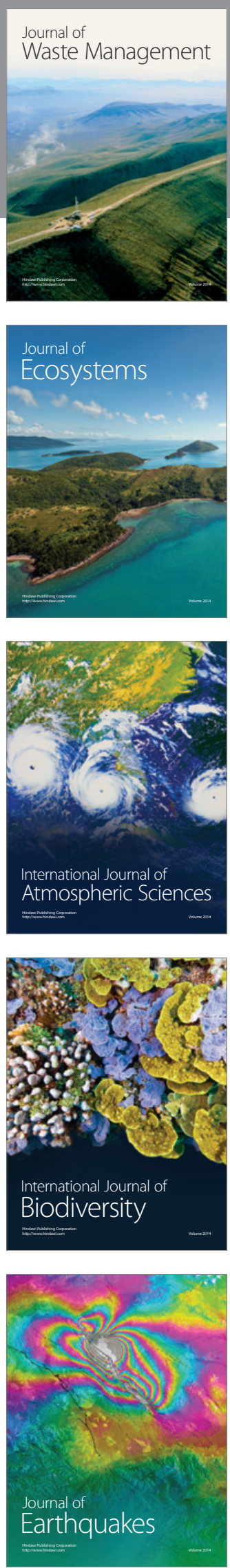
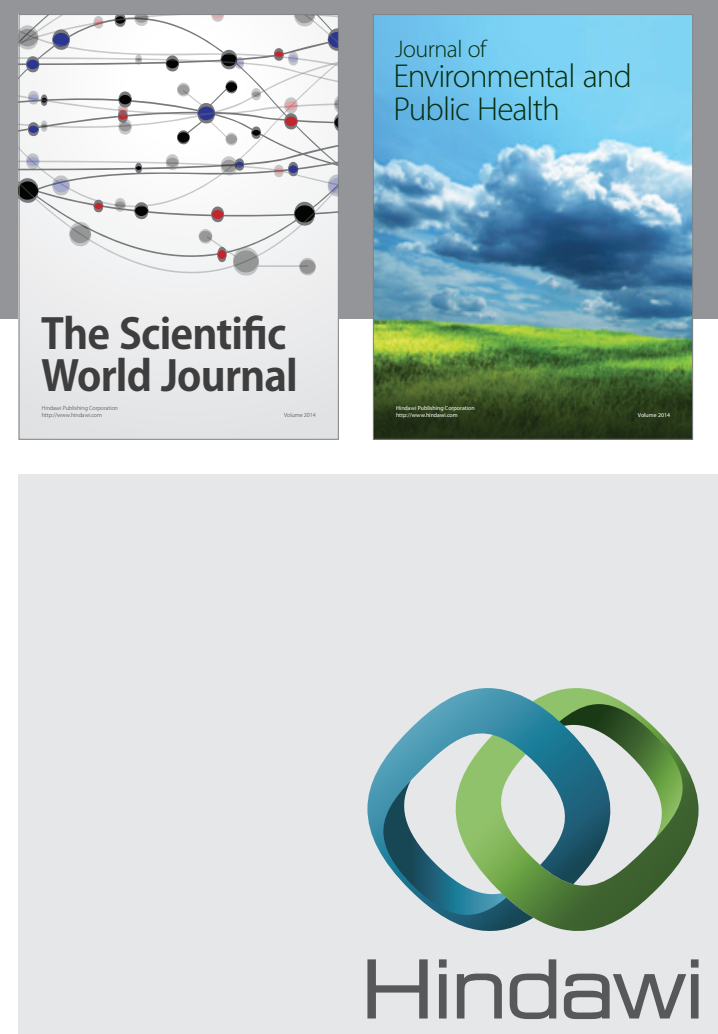

Submit your manuscripts at

http://www.hindawi.com
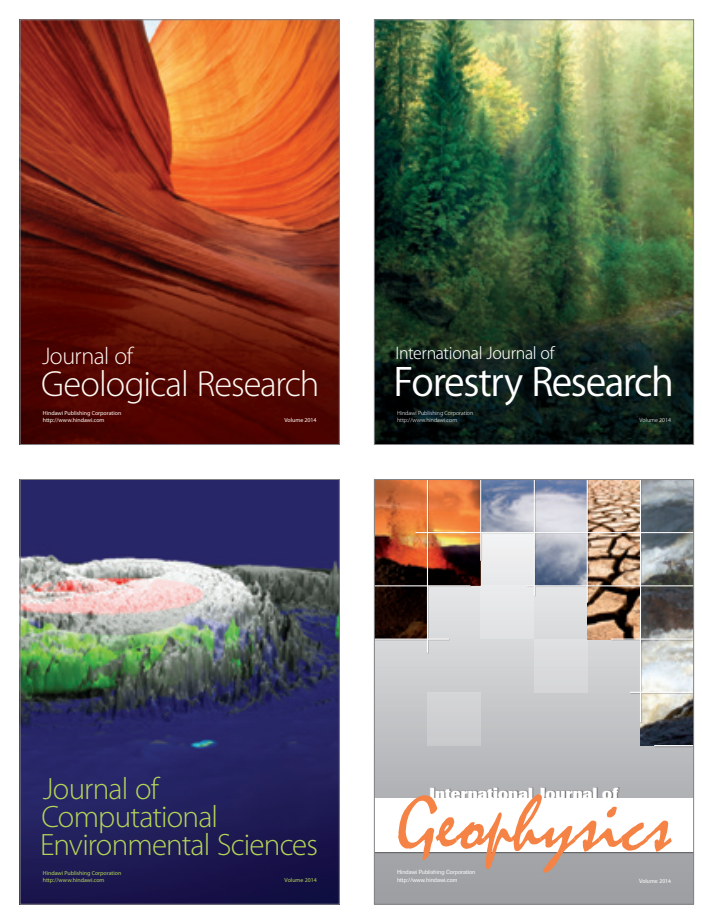
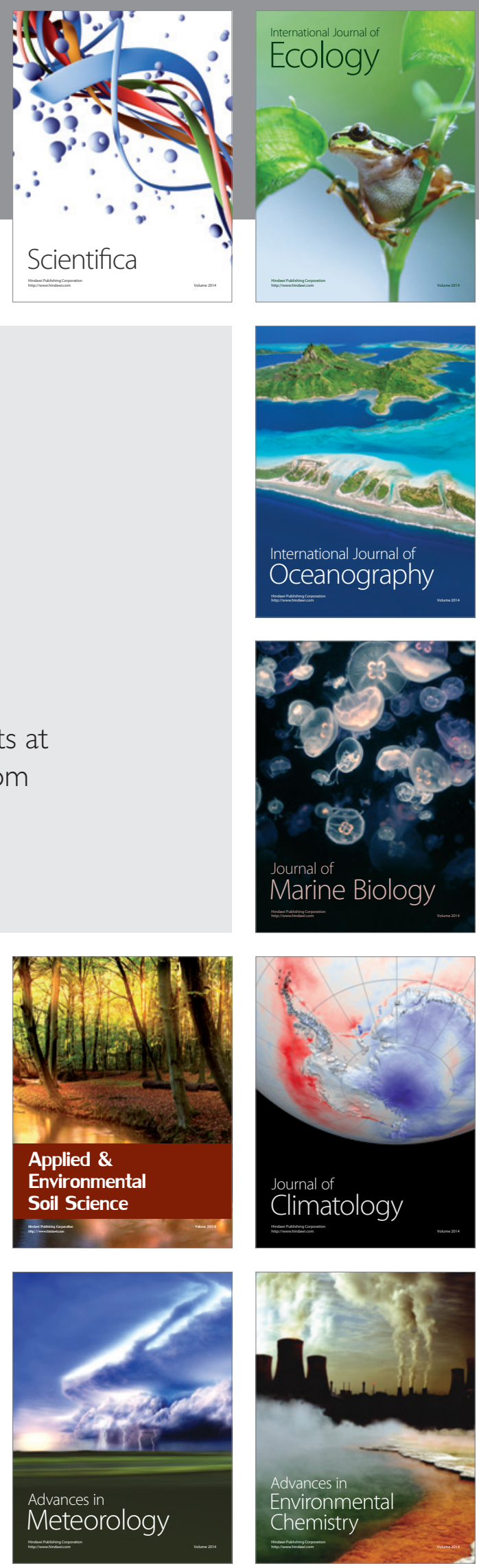